\title{
Acute hemicerebellitis in a young adult: a potential pitfall
}

\author{
Hemicerebelite aguda em adulto jovem: uma armadilha em potencial \\ Pedro Henrique Almeida FRAIMAN ${ }^{1,2}$, Manuel MOREIRA-NETO³, Clecio GODEIRO-JUNIOR²
}

A 20-year-old man presented with a new headache for 21 days. His neurological examination showed mild right-side ataxia while walking in tandem. Brain MRI revealed extensive hyperintensities in the right cerebellar hemisphere in FLAIR/ T2WI and moderate choline peak and low NAA (Figure 1). The viral and rheumatological panels in serum were negative. After 8 months, there was lesion regression (Figure 2). Combined lesion evolution and spectroscopy findings, inflammatory nature was suggested.

The diagnosis of hemicerebellitis is uncommon in adults but more common in children ${ }^{1}$. Spectroscopy could help differentiate from mimicking neoplastic lesions (e.g., Lhermitte-Duclos syndrome $)^{2}$ and avoid unnecessary interventions.

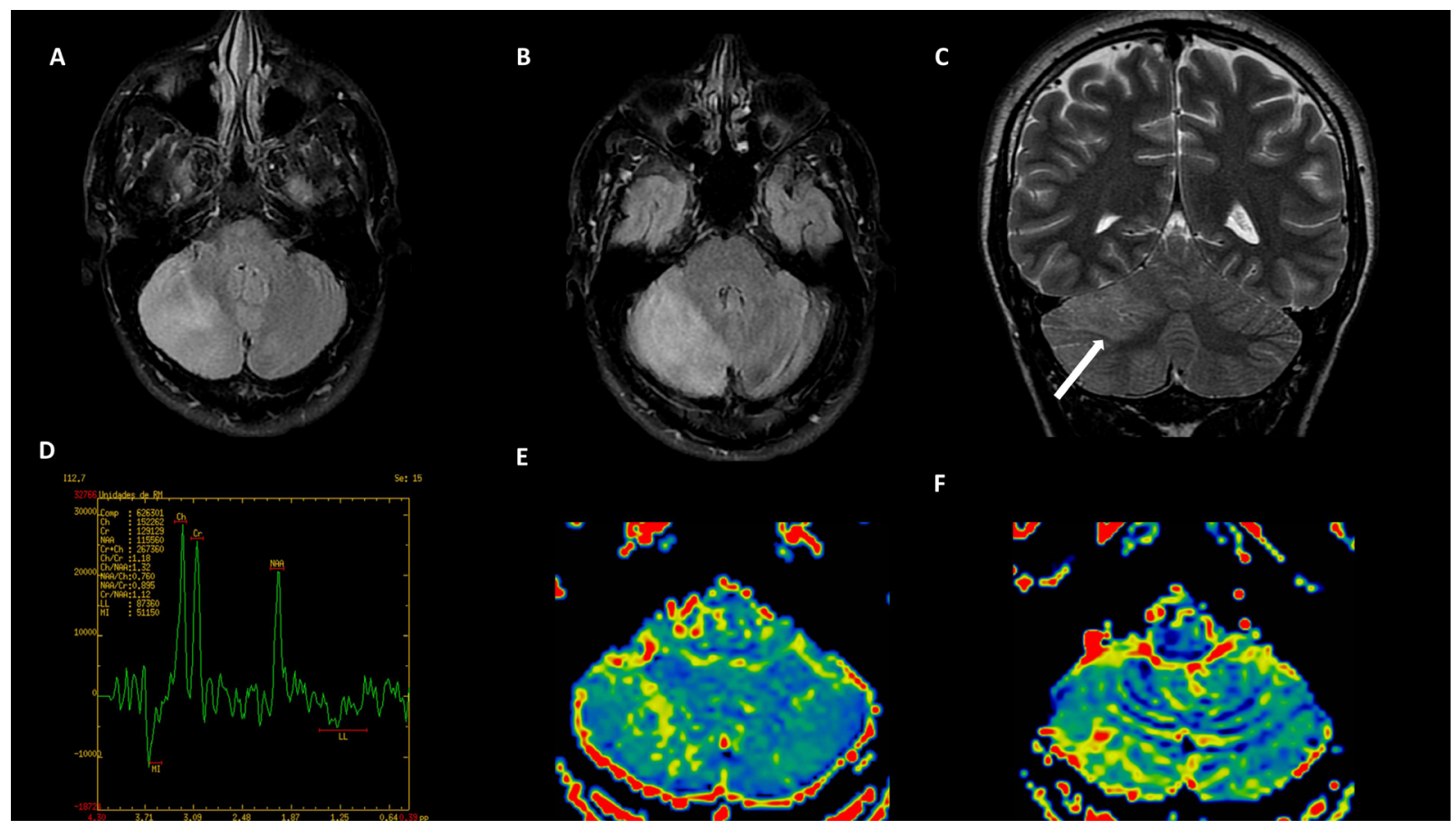

Figure 1. Acute hemicerebellitis neuroimaging features. (A, B) FLAIR/T2WI of posterior fossa revealing extensive hyperintensity area in right cerebellar hemisphere, mainly in posterior and lateral portions, with mild expansive effect; (C) GRE/T1WI showing increased vascular enhancement after contrast, suggesting hyperemia. (D) Multivoxel Proton MRI spectroscopy (long time of 144 ms) presenting high Choline peak, low lactate peak, low NAA and myo-inositol. High choline is not expected in Lhermitte-Duclos syndrome, as seen in this case, helping the differential diagnosis. (E, F) Cerebral Blood Flow (CBF) and Cerebral Blood Volume (CBV), respectively, increase in the right cerebellar hemisphere compared to the left hemisphere.

\footnotetext{
${ }^{1}$ Universidade Federal de São Paulo, Escola Paulista de Medicina, Departamento de Neurologia e Neurocirurgia, São Paulo SP, Brazil.

¿2Universidade Federal do Rio Grande do Norte, Hospital Universitário Onofre Lopes, Divisão de Neurologia, Natal RN, Brazil.

${ }^{3}$ Universidade Federal do Rio Grande do Norte, Hospital Universitário Onofre Lopes, Divisão de Radiologia, Natal RN, Brazil.

PHAF (D) http://orcid.org/0000-0002-5250-8602; MMN (D) http://orcid.org/0000-0002-3478-5323; CGJ (D) http://orcid.org/0000-0002-4312-1633

Correspondence: Pedro Henrique Almeida Fraiman; Email: fraiman@ufrn.edu.br.

Conflict of interest: There is no conflict of interest to declare.

Authors' contributions: PHAF: analysis and interpretation, writing and drafting the manuscript; MMN, CGJ: critical revision of the manuscript for intellectual content.

Received on April 12, 2021; Received in its final form on May 26, 2021; Accepted on June 03, 2021.
} 


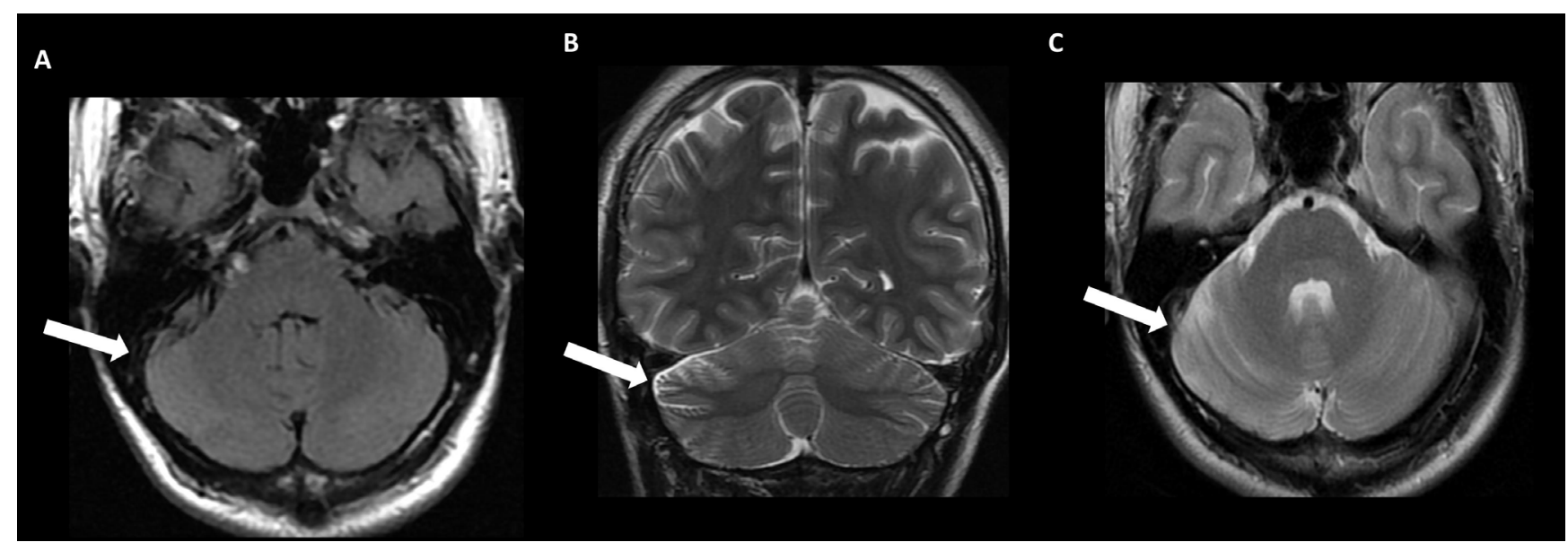

Figure 2. Follow-up study after 8 months. (A, B, C) Follow-up study after 8 months revealing regression of previous alterations and a mild cortical atrophy in lateral and superior right cerebellar hemisphere (thick arrows). Regression of lesions with mild atrophy is compatible with natural evolution of hemicerebellitis in opposition of progressive lesions (e.g. tumors).

\section{REFERENCES}

1. $\quad$ Suzuki K, Nakamura T, Numao A, Fujita H, Komagamine T, Nagashimi T, et al. Acute hemicerebellitis in a young adult: a case report and literature review.J Neurol Sci. 2014 Dec 15;347(1-2):364-7. https:// doi.org/10.1016/j.jns.2014.10.016
2. Guerrini L, Belli G, Cellerini M, Nencini P, Mascalchi M. Proton MR spectroscopy of cerebellitis. Magn Reson Imaging. 2002 Oct;20(8):619-22. https://doi.org/10.1016/S0730-725X(02)00600-8 